\title{
Micro-teaching 2.0: Technology as the classroom
}

\author{
Susan Ledger \\ Murdoch University \\ John Fischetti \\ University of Newcastle
}

\begin{abstract}
Currently pre-service teachers (PSTs) practise teaching by interacting in real-life situations naturally occurring within variable school-based practicums. These are not ideal contexts for beginning teachers because they put novices in situations with real students before demonstrating capability, feedback is often not at point of need and they do not provide all students with similar experiences. Simulation and micro-teaching combine to provide a technological solution to bridge the gap between graduate preparation and real application. This study draws on situated learning and reflective practice ideologies to critique and problematise Micro-teaching 2.0 - a combination of traditional micro-teaching practices and human looped simulations. The findings reveal increased self-efficacy of PSTs $(n=376)$ and identify the benefits and challenges of Micro-teaching 2.0 for initial teacher education programs. Micro-teaching 2.0 proved to be an effective diagnostic tool for identifying the specific needs of PSTs and a preparatory tool for real-life placements. The controlled learning environment addresses previous issues related to the variability of contexts and subsequent moderation of individual capabilities. The findings are timely as the teaching profession continues to be scrutinised and where technological advances continue to offer choice, challenges and creative options for educators.
\end{abstract}

Implications for practice or policy:

- Micro-teaching combined with human in the loop simulation provides a powerful and safe learning environment to practice the art and science of teaching.

- Simulation affords initial teacher educators a controlled learning environment for effective moderation and diagnosis of practice.

- Simulation in Education for the current generation of students builds on previous embodied, gaming and immersive learning experiences where the interaction is true and realistic.

- Simulation technologies and micro-teaching combine to bridge the gap between graduate preparation and real-life application.

Keywords: Micro-teaching, Simulation, Initial Teacher Education, Mixed reality learning environments, Preservice teacher self-efficacy, Reflective practice, Practice Theory

\section{Introduction}

Initial teacher education (ITE) programs within higher education contexts continue to draw interest, debate, review and recommendations from around the globe (Darling-Hammond, 2016; Ell et al., 2019). Teacher selection, teacher quality and classroom preparedness have remained key areas of concern for researchers, policy writers and social commentators (Louden, 2008; Mayer et al., 2015). Much of the scrutiny has centred on the quality of pre-service teachers (PSTs) and their readiness for the workforce (DarlingHammond, 2016; Schleicher, 2011). The readiness concern of graduate teachers evidenced in other countries and the Organisation for Economic Co-operation and Development is mirrored in Australian educational discourse. Australia's recent government call for "classroom ready" graduates highlights ongoing issues and concern related to the quality and variability of graduates and the schools in which they are placed (Department of Education and Training, 2017).

The corresponding importance of school readiness for those receiving and supporting pre-service and graduating teachers is negated by the variability that exists within our school systems (Le Cornu, 2015; Ledger, 2017). Issues surrounding the variability of school experiences for PSTs and the provision of suitable high-quality mentors is a perennial challenge for coordinators of ITE programs charged with 
placing PSTs (Bahr \& Mellor, 2016). Compounding the situation is the increased number of PST enrolments within ITE programs and decreasing numbers of quality professional experience placements (Ure, Hay, Ledger, Morrison, Sweeney, \& Szadura, 2018). As a result, universities are exploring alternative approaches to support traditional practicums in their quest to better prepare their graduates (Bahr \& Mellor, 2016).

Traditional and emerging approaches employed to prepare PSTs have typically drawn on situated learning theory (Lave \& Wenger, 1991) and reflective practice ideologies (Dewey, 1933; Schön, 1983). Both ideologies assume knowledge is acquired by doing (Kemmis, et al., 2014). However, professional experience for PSTs occurs within indeterminate situations characterised by complexity, uncertainty and variability of setting. Diverse school contexts, variability in the quality of mentors and place-based demands impact the doing acquired and required by PSTs. This variability of contexts makes researching the potential impact of teaching and learning approaches challenging. The diversity of contexts also makes it difficult to identify the common characteristics, benefits and challenges of ITE strategies and self-efficacy of PSTs. Kraft, Marinell, and Yee (2016) highlight how school contexts have a significant impact on teachers:

School context measures are stronger predictors of teacher turnover than individual teacher traits or the average characteristics of students in a school... studies examine somewhat differing sets of school context dimensions, several of these dimensions consistently emerge as the strongest predictors, including the quality of school leadership, the degree of order and discipline in a school, and the support that collegial relationships provide. (p. 2)

Although context is considered influential in its prediction of teachers' self-efficacy and teacher turnover rates, Merghler and Tangen (2010) contend that PSTs' classroom management and personal teacher traits are the strongest contributing factors impacting teacher self-efficacy. Moreover, Grossman (2005) suggests the connections between theory and practice are not made explicit in teacher training programs and that this impacts the development of graduate teachers' self-efficacy. Bridging the perceived gap between learning and doing and producing classroom-ready graduates are desired outcomes of ITE programs. The variability of PSTs' self-efficacy and variability of experiential classrooms is of concern and adds complexity to the process.

A controlled learning environment such as a simulation removes some of the complexity and variance experienced in real-life classroom settings. It also addresses issues related to self-efficacy of teachers in response to the challenges of bridging the theory-practice divide as suggested by Grossman (2005). The controlled, non-threatening, synchronous learning environment of simulations allows for valid and reliable moderation of PST performance and self-efficacy (Dieker, Lignugaris-Kraft, Hynes, \& Hughes, 2016). Furthermore, simulations offer the opportunity to implement, observe and capture the effectiveness of situated learning and reflective practice approaches, which are typically more difficult to measure within the variability of real-life contexts.

Situated learning has antecedents in the work of Gibson's (1986) theory of affordances and Vygotsky's (1980) social learning, where perception of the environment inevitably leads to specific courses of action. These actions are often enacted through embodied learning activities, technology-based learning activities or real-life contexts such as practicums and simulation rather than abstract concepts. Terms and approaches including cognitive apprenticeship, embodied learning, practice theory, gradual release of responsibility, problem-solving, authentic tasks and assessment, scenario-based learning and action research represent how situated learning theory has been applied within ITE programs. Technology is also playing an important role within this space with the introduction of simulation and online virtual classrooms such as Second Life (Gregory \& Masters, 2012), simSchool (Tyler-Wood, Estes, Christensen, Knezek, \& Gibson, 2017) and more recently human in the loop (HITL) simulated technologies by TeachLivE ${ }^{\mathrm{TM}}$ and Mursion ${ }^{\mathrm{TM}}$ (Dieker, Rodriquez, Lignugaris-Kraft, Hynes, \& Hughes, 2014; Ledger, Ersozlu, \& Fischetti, 2019).

Reflective practice, like situated learning, involves knowledge acquisition through experience. However, the focus is not on the interaction but more importantly on the recognition of the paradigms, assumptions, frameworks, patterns of thought and behaviour that shape our thinking and actions. Beauchamp's (2006) analysis of reflective practice definitions highlights the lack of clarity and ambiguity of the term. Dewey (1933) argued that experience and interactions build one's capability to deal with a range of situations. 
Schön (1983) purported that knowledge of the situational context in addition to actual practice is important to develop spontaneous skilful execution. Spontaneous skilful execution distinguishes between reflectionin-action, where decisions are happening on the spot and action appears intuitive, and reflection-on-action, which occurs after an incident or experience and demands an additional time commitment. Beauchamp (2006, p. 106) highlighted definitive aspects of reflective practice as "conceived as a process concerning a particular object in view of achieving a goal". Moreover, debate exists about whether reflection is seen as action (Dewey, 1933; Schön, 1983), emotion (Valli, 1997) or levels as presented by Van Manen's (1977) technical, practical and critical reflectivity and Zeichner's (1987) factual, prudential, jurisdictional and critical levels of reflective practice. A combination of reflective practices adds to the many models and stages of reflection used within ITE programs, supporting Zeichner's (1994) belief that "all of the domains of reflection are important and necessary" (p. 14).

Micro-teaching, a strategy widely used across teacher training programs, combines both reflective practice and situated learning approaches. Micro-teaching is a condensed lesson plan used to practise, rehearse and reflect on action (Arsal, 2014; Ledger et al., 2019). It is often delivered within a role-play context for realtime feedback and reflection. Micro-teaching provides a platform for both mastery experiences and vicarious experiences for PSTs, elements considered essential for the development of teacher self-efficacy (Bandura, 1997; Griffiths, 2016). The strategy has been adopted within a range of contexts and disciplines such as health, science and medical education (Remesh, 2013). Micro-teaching resembles the Japaneseinspired collaborative reflective practice entitled lesson study originating in the $1880 \mathrm{~s}$. Manifestations of lesson study have permeated ITE programs and teaching practices around the globe over the last century (Mergler \& Tangen, 2010): Micro-teaching emerged in the 1960s at Stanford University and featured reflective collaborative practices (Cooper \& Allen, 1970); lesson studies have been adapted in the United Kingdom (Dudley, 2011); Micro-teaching and research-based lessons are embedded in the United States (Lewis, 2002); and in Australia adaptations include productive pedagogies (Gore, Griffiths, \& Ladwig, 2004) and more recently Quality Teacher Rounds (Gore, 2018). These collaborative models of reflective practice and situated learning coupled with their associated corpus of research respond to Collin, Karsenti, and Komis's (2013) call for more sound validated methodologies and clear concepts when implementing reflective practice processes, objectives and goals. However, micro-teaching, like lesson study, remains partially embedded, somewhat misunderstood and under-researched across ITE programs (Griffiths, 2016).

This article introduces Micro-teaching 2.0, a combination of traditional micro-teaching methods and new simulation technologies to address the preparedness and quality of teaching graduates as they transition into real-life school contexts.

\section{Contextualising Micro-teaching 2.0: Technology as the classroom}

Micro-teaching, a universal approach for reflective practice conceptualised at Stanford University in the early 1960s, has continued to offer ITE programs a valuable preparatory process for PSTs' moving into realclassroom contexts (Allen \& Eve, 1968; Arsal, 2014; Griffiths, 2016). Cooper and Allen (1970, p. 1) defined micro-teaching as:
A teaching situation which is scaled down in terms of time and numbers of students. Usually this has meant a 4-24minute lesson involving 4-5 students. The lesson is scaled down to reduce some of the complexities of the teaching act, thus allowing the teacher to focus on selected aspects of teaching. Frequently, one Micro-teaching episode includes teaching a lesson and immediate feedback on the teacher's effectiveness. This feedback may come from video-or audiotape recordings, supervisors, pupils, colleagues, or from the teachers' self- perceptions. Some of the variable aspects of Micro-teaching include lesson length, number of students, the amount and kind of supervision, the use of video-or audiotape recordings and number and types of pupils.

Epistemologically, Micro-teaching positions itself within experiential-based situated learning theories and reflective practice paradigms. It situates experience at the core of the learning process; a dynamic continuous process of change that relies on self-reflection for improvement (Impedovo, \& Khatoon Malik, 2016). Micro-teaching is reported to effectively bridge the school placement gap (Griffiths, 2016). The principles of Micro-teaching and reflective practice underpin many teacher preparation programs (Donnelly \& Fitzmaurice, 2011), thus helping PSTs who struggle to bridge the perceived theory-practice divide 
(Grossman, 2005. Micro-teaching experiences can be both process and product involving the transference of knowledge or skills via dialogic engagement, role play, rehearsal and feedback (Allen \& Eve, 1968).

Micro-teaching has many benefits and has long offered ITE programs a useful preparatory tool for real-life classrooms. Cooper and Allen's (1970) critique of Micro-teaching research found that performance in a Micro-teaching situation can accurately predict subsequent classroom performance. Micro-teaching originally involved small groups of students in schools to practice the delivery of micro lesson plans and behaviour management strategies. This proved to be problematic in the 1960s due to the difficulty of accessing school students for trial lessons (Allen, 1980). To overcome this issue, university peers were used instead of actual school students. Micro-teaching focused on developing a repertoire of teaching skills for PSTs using a teach/critique and re-teach/re-critique approach (Griffiths, 2016). Variations of the peer Micro-teaching model have continued to be employed with benefits outweighing challenges (Vare, 1993). To be successful, however, Micro-teaching requires both teacher and learner behaviours to be operationally defined and the desired interactions be derived from a theoretical rationale (Cooper \& Allen, 1970).

Various forms of Micro-teaching have been used extensively in initial teaching programs, but most PSTs practise their lesson planning, behaviour management and communication skills by interacting within reallife situations that are naturally occurring and context specific within practicums (Ledger et al., 2019). Although considered essential experiences, they are not ideal for beginning teachers and require reculturing and redesign (Le Cornu, 2016). Practicums put novices in situations with real students before they have demonstrated the knowledge, skills and dispositions to be effective; feedback is often not at point of need; they do not provide the full range of situations that occur in diverse classroom contexts; and effective moderation is difficult across the cohort (Ledger et al., 2019). Micro-teaching offers a solution to the inherent variability that occurs in these real-life context-based experiences.

Two decades after the introduction of Micro-teaching in ITE programs at Stanford University, Newton's (1983) study "Computer Simulation in Teaching Training" explored the advantages of interacting with computers in ITE in comparison to Micro-teaching techniques. His conclusions about simulation highlighted:

(1) the consequences of lack of skill are not so traumatic for student teacher,

(2) the skill or group of skills can be focused upon to any desired degree, either excluding others or allowing them varying degrees of intrusion,

(3) its patience is inexhaustible. (p. 43)

However, Newton did not explore the possibility of combining micro-teaching with computers; rather computers and micro-teaching were offered as binaries to support PSTs preparing for practice. Technological advances now offer ITE program providers the opportunity to combine micro-teaching with more sophisticated technological choices than traditional student-peer interactions or computer-based asynchronous experiences. As technologies continue to become more sophisticated and education more complex, opportunities for incorporating technology into ITE have increased (Fouts, 2000).

\section{Micro-teaching and simulation in teacher education}

With the emergence of simulated learning environments, technology has transitioned from being used in the classroom to technology as the classroom. Simulation has been used successfully in many learning contexts including flight training, engineering, tactical warfare and medicine (Dalgarmo \& Lee, 2010; Lui, Dede, Jacobson, \& Richardson, 2017), yet has had limited uptake within ITE programs. Simulation has the capacity to address the self-efficacy of PSTs and the variability of experiences afforded in real-life contexts (Chini, Straub, \& Thomas, 2016). Although pockets of trials and research do exist in relation to virtual and mixed reality simulation software and programs (Christensen, Knezek, Tyler-Wood, \& Gibson, 2011; Dieker et al., 2016; Gregory \& Masters, 2012) no comprehensive or widespread adoption or uptake of simulation within nation states is evidenced.

Research on educational simulation for ITE programs has been limited due partly to the diversity of simulation types, ever-changing technologies and whole-of-program uptake in universities. Early adopters have trialled simulation in ITE programs including but not limited to the research on Kindergarten Classroom (Ferry et al., 2005); simSchool (Christensen et al., 2011); Second Life (Gregory \& Masters, 
2012); TeachLivE ${ }^{\mathrm{TM}}$ (Dieker et al., 2014) and Mursion ${ }^{\mathrm{TM}}$ (https://www.mursion.com/services/education/) and SimLab ${ }^{\mathrm{TM}}$ (Ledger, 2017; Murdoch University, n.d.).

The simulation options adopted within ITE programs tend to be single-user virtual environments such as simSchool and SimClass and 3D virtual reality environments accessed via headwear and glasses (Christensen et al., 2011). More recently, a range of virtual and mixed reality learning environments have been trialled, including Second Life, Teacher Talk and Kognito Interactive (https://kognito.com/) (Ledger et al., 2019). The introduction of HITL synchronous simulation option currently operates in limited universities around the globe with the majority programs offered in the United States. TeachLivETM is one of the original HITL programs developed at the University of Central Florida; its commercial partnership with Mursion TM provides site licences that extend around the globe. Murdoch University is the only licenced HITL technology provider in Australia but has partnered with the University of Newcastle and the University of Western Australia for research and pedagogical purposes (Ledger, 2017; Ledger et al., 2019).

Although research on educational simulation for ITE programs has been limited due partly to the diversity of simulation types, ever-changing technologies and whole-of-program uptake in universities (Ledger et al., 2019, many commonalities exist in the findings: simulated learning environment learners move at their own rate, rehearse and perfect their skills, build confidence in their personal abilities and in turn increase their teaching self-efficacy and reflective practice capacity (Christensen et al., 2011; Gregory \& Masters, 2012; Ledger et al., 2019; Schwabb, 2017; Straub, Dieker, Hynes, \& Hughes, 2015). These benefits align with findings from other professions where behaviour and mastery of skills are paramount and practised (Choi et al., 2017).

Although the realm of simulation is moving towards the exploration of artificial intelligence (Schwabb, 2017), humans will never be excluded entirely from the adaptation loop of new technologies (Gil, Pelechano, Fons, \& Albert, 2016). HITL technologies refer to a human process used to validate and improve artificial intelligence; they have many applications and distinct differences. In simulation technologies HITL refers to a human interactor working behind the scenes to enable the synchronous voice and body responses. An HITL learning environment consists of four components - interactor, avatars, students and observers connected via computer and Internet access. Purposefully trained interactors (improvisation actors and puppeteers) operate and control the HITL functionality (Figure 1), allowing real-time dialogic engagement to occur (Nagendran, Pillat, Kavanaugh, Welch, \& Hughes, 2014). The unique role of the interactor in classroom simulation remains the point of difference over earlier simulation models.

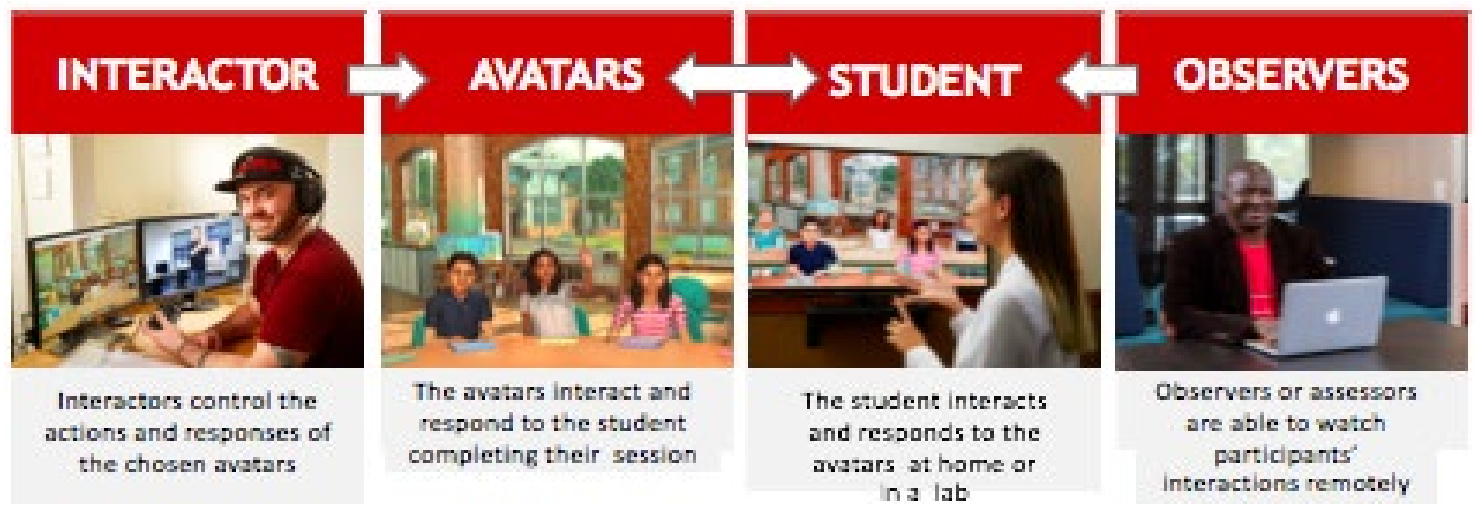

Figure 1. Components of SimLab HITL simulation at Murdoch University (Ledger, 2017)

The operational components of HITL simulation are shown in Figure 1. The interactor controls the responses of the avatars based on the specific scenario or context provided by the academic. The PST conducts a micro-teaching lesson and practises specific elements of their performance as identified. Feedback and moderation are provided by the academic on PST performance. The experiential interaction is recorded for self-reflection. The process is repeated if required.

The connectivity of components is presented in Figure 2; two computers with webcams (one for the interactor and one for the student), an Internet connection (used for Zoom or Skype) and a microphone system. Zoom interactions are accessed within an on-campus lab or remotely via Skype or Zoom on any 
device. The flexible delivery enables access and comparability of experiences between internal and external enrolled PSTs (Ledger, 2016).

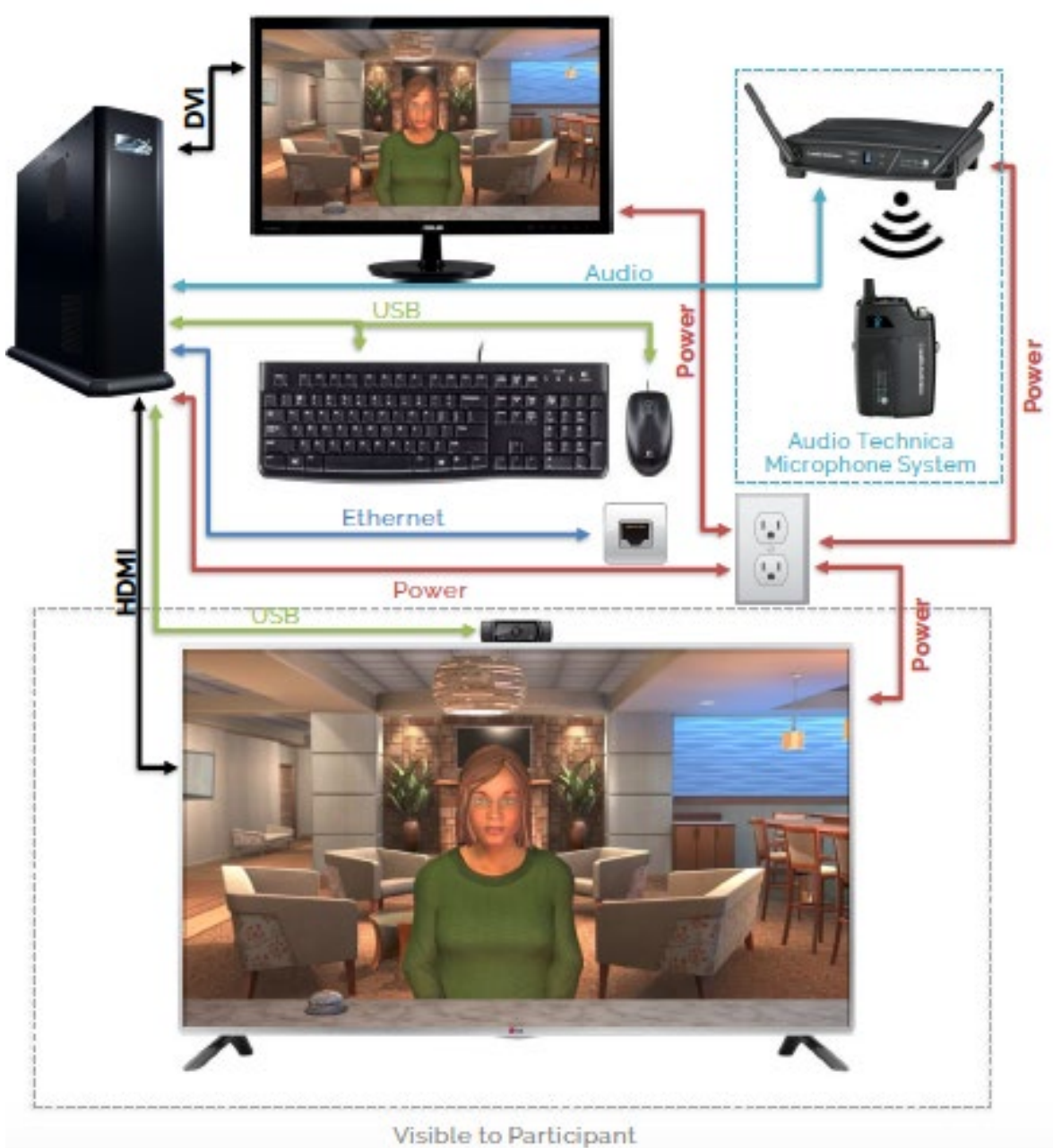

Figure 2.SimLab@Murdoch wiring diagram (Mursion, 2017, p. 2)

Insight into the use of HITL simulation and its impact on PSTs is revealed in a recent systematic review of 100 publications between 2012 and 2017. The benefits of simulation outweighed the challenges within the findings, with reports capturing its effectiveness to change the practice and build the confidence of PSTs (Ersozlu, Ledger, Mayne, \& Wildy, 2019). Much of the research targeted PSTs rather than actual ITE programs, implementation processes or teaching methods. The studies were predominately single subject experimental design using observation and questionnaires as chief data collection tools. Micro-teaching research is not explicitly addressed within these studies; moreover, no empirical data has been collected on HITL technologies within an Australian context.

\section{Micro-teaching 2.0}

The concept of Micro-teaching 2.0 is introduced as a combination of traditional micro-teaching strategies hailing from Stanford University in the early 1960s (Allen \& Eve, 1968) and HITL simulation technologies. It differs from previous combinations of micro-teaching and technologies in that traditionally technology was used to video or capture the simulated experience (recordings) or replicate the experience within an online environment (Second Life, simSchool). Micro-teaching 2.0 adopts technology as the classroom rather than in the classroom. HITL technologies remove the need for peers to role-play and in turn eliminate issues related to anxiety, human fragility and power inequities previously experienced in peer-to-peer role-play scenarios (Donnelly \& Fitzmaurice, 2011). Micro-teaching 2.0 is used for individuals to practise, rehearse and reflect on the skills, art and science of teaching, including opportunities to engage with parents, 
colleagues and superiors. The synchronous capabilities of HITL technologies are its main point of difference.

Bahr and Mellor (2016) suggest that teacher education programs have had limited change over the last few decades and limited uptake of technology, which seems at odds with the rapidly changing technological backdrop of creativity, commodity and utility afforded by the fourth Industrial Revolution (Schwabb, 2017). In Hixon and So's (2009) field experience taxonomy for PSTs, Micro-teaching 2.0 would fall into Type II field experience. Type I refers to concrete, direct experiences in reality (physically present in schools); Type II refers to vicarious, indirect experiences with reality (videos, observations, videoconferencing); Type III are abstract experiences that model reality (but lack interaction with teachers, students). Current ITE programs preference Type 1 in their programs (Hixon \& So, 2009).

For the purposes of this study the term Micro-teaching 2.0 signifies an amalgam of previous micro-teaching approaches coupled with HITL simulation (Ledger et al., 2019). It is adopted in ITE programs as a preplacement tool to improve the self-efficacy of PSTs and provide a controlled learning environment to plan, rehearse, reflect and moderate practice.

\section{Aims and research questions}

The research design used situated learning and reflective practice paradigms as a backdrop. It aims to explore the benefits and challenges of Micro-teaching 2.0 and its impact on the self-efficacy of PSTs preparation for real life placements. It captures initial Micro-teaching 2.0 situated learning experiences and PST's reflections on their practice.

A mixed-method combination of research components was employed to gain insight into Micro-teaching 2.0 as a preparatory tool for placements within ITE. The following questions guided this research:

(1) What is Micro-teaching 2.0? Define, critique and problematise. (literature review)

(2) What are the benefits and challenges of Micro-teaching 2.0? (literature review, observation, questionnaire responses)

(3) What is the impact of Micro-teaching 2.0 on the self-efficacy of PSTs? (questionnaire responses, observations)

\section{Methods}

This mixed-method study explored the situated learning experiences of first-year PSTs within a Microteaching 2.0 context through reflective practice processes. Zeichner (1994) encourages a combination of reflective practices within ITE, knowing experience and interactions build one's capability to deal with diverse situations. Perspectives were sought from literature, observation of PSTs within the synchronous simulation environment and a questionnaire conducted to capture pre-simulation, actual experience and post-placement self-efficacy. In the virtual world space, measuring performative data enables observers to see what students can do or know, whereas a student's self-efficacy has been shown to be a strong predictor of future achievement (Henderson, Huang, Grant, \& Henderson, 2012). Situated learning enables observation of what Schön (1983) considers reflection-in-action, whilst questionnaires enable us to capture reflection-on-action.

\section{Participants and processes}

All first-year ITE students from Murdoch University and the University of Newcastle were invited into the study prior to embarking on their first practicum. Of the total 520 students across the two universities, 376 gave consent for all components of the study: construction of a micro-lesson plan; 10-minute microteaching lesson of choice (simulation); observation by academic (performance \& possibilities); postpracticum questionnaire (simulation \& practicum). The questionnaire was conducted post-practicum to capture impact and application (practicums occurred up to a week after the simulation). 
The goal of the questionnaire and observation sheet (Ledger et al., 2019) was to capture:

(1) Confidence levels before, during and after simulation/practicum;

(2) Outline of chosen teaching strategy;

(3) Effectiveness of Micro-teaching lesson - presence, effective introduction, sustained communication;

(4) Engagement - gaining attention, questioning, appropriate responses, maintaining interest;

(5) Body language and voice - varied tone and expression, appropriate to situation, clear and audible;

(6) Feedback - able to draw out knowledge, respond to question, articulates expectations, able to redirect off-task behaviour;

(7) Rapport building - eye contact, use of names, interaction, positive/smiles;

(8) What do you consider the benefits or challenges of Micro-teaching 2.0?

\section{Data collection}

PST self-efficacy was captured using an online self-reported questionnaire conducted after the Microteaching 2.0 task (virtual classroom context) and corresponding professional experience (real classroom context). Observations of the 10-minute Micro-teaching sessions assisted in the diagnostic moderation of the first-year cohort. The questionnaire was informed and structured by situated learning and reflective practice elements; the ten questions provided a range of ways for the PSTs to reflect on their interactions. A rating scale $(1-4$, where $1=$ not at all confident, $2=$ somewhat confident, $3=$ confident, $4=$ very confident) was combined with supporting comment sections. An open-ended final question captured the benefits and challenges of Micro-teaching 2.0.

\section{Data analysis}

The action research paradigm espouses that knowledge is gained through action and for action (Tripp, 2005); situated learning is positioned within this realm. Capturing PST self-efficacy before, during and after a Micro-teaching 2.0 produced valuable empirical data for analysis, which was conducted systematically and sequentially to generate conclusions and future research possibilities.

The PST reflections were analysed using Lichtman's (2006) 3Cs - code, categorise and develop concepts. These findings were then aligned to key theoretical concepts related to situated learning and reflective practice using Van Manen's (1977) technical, practical and critical levels of reflection. Coding of data was conducted using NViVo. Final analysis of the data is presented in response to the research questions. Recommendations are provided as springboards for further research from these findings.

\section{Findings}

The findings are presented in three parts aligned to the research design. First, key data from the questionnaire is presented in a range of formats and key concepts revealed. These findings are aligned to key concepts from the literature review related to situated learning and reflective practice. Final discussions are presented in relation to the research questions highlighting the benefit and challenges of Micro-teaching 2.0 and the self-efficacy of PSTs engaged in the process.

\section{Questionnaire}

A total of 376 first-year ITE students completed a self-efficacy questionnaire consisting of eight questions, of which five used a 4-point rating scale and supporting comments, one required uploading of the lesson plan delivered in the Micro-teaching session and included two reflections on their performance, and one open-ended question related to benefits and challenges.

\section{Question 1}

Question 1 required self-reported reflections on PSTs' confidence to teach before, during and after simulation and practicum. Results indicated that the majority of PSTs (85\%) were "not at all" or "somewhat confident" before experiencing Micro-teaching 2.0, whereas during the interaction only $70 \%$ were "not all" 
or "somewhat confident". The final reflection after the simulation and practicum saw less than $20 \%$ "not at all" or "somewhat confident". The variance of very confident PSTs rose from 2 to $32 \%$ (Figure 3).

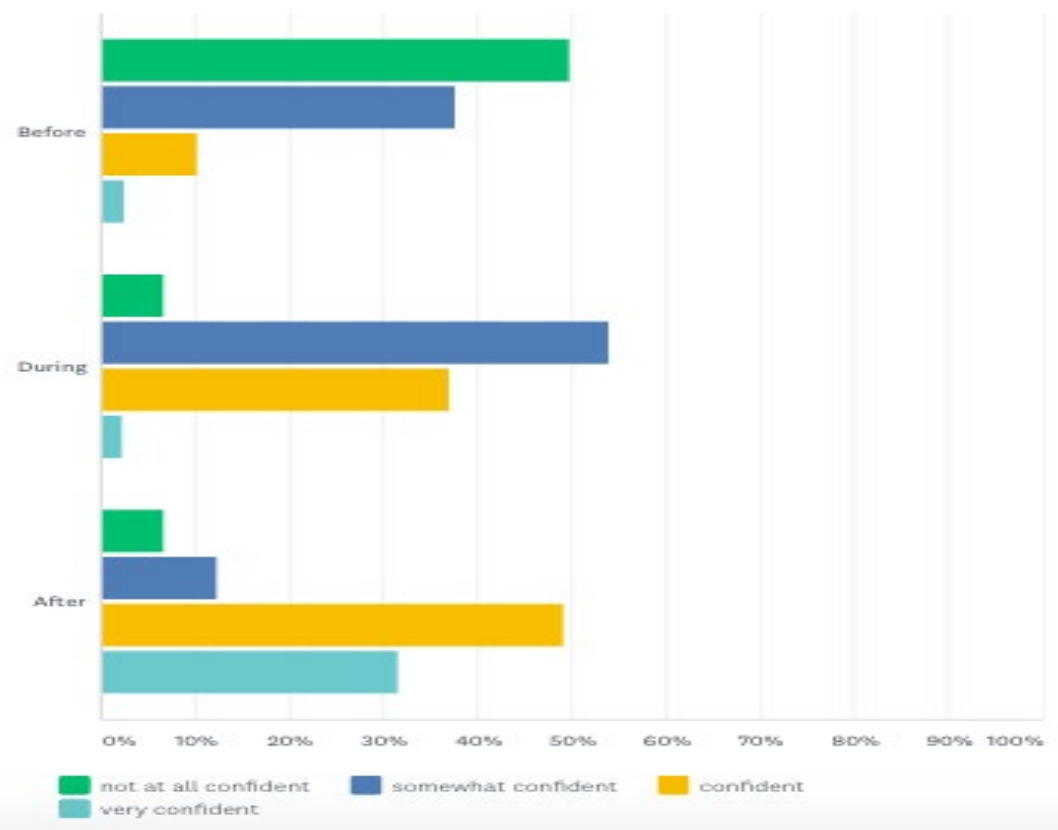

Figure 3. Confidence levels before, during and after simulation experience

Question 2

The second question required PSTs to outline the chosen teaching strategy for their micro-lesson. A word cloud was constructed of the submissions (Figure 4), revealing a limited focus or clear lesson intent rather than a focus on the strategies or subjects introduced, for instance, questioning, instructions, brainstorming, discussion, direct instruction, book reading, English and reading.

\section{Micro-teaching Session Good Behaviour Group Discussion Gain an Understanding InstructionS Effective Questioning Prior Knowledge Literacy Classroom Guided Reading Asking Characters Lesson English Engaged Real Life Teaching Brainstorming $_{\text {Ba }}$ Question and Answer Types of Questions Focussed ${ }_{\text {student centered }}$ Class Discussion Life Experience $_{\text {Dis }}$

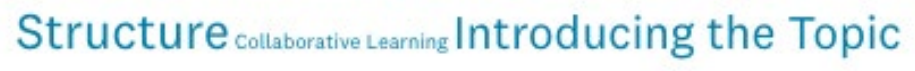

Figure 4. Word cloud based on responses

Attention also focused on students' prior knowledge, introductions and good behaviour. Only a few students referred to the three components of lesson structure, for example, "I introduced students to a framework for writing paragraphs, explained diagram, modelled a sample and then gave them a chance to try themselves. I concluded by getting them to identify key components".

General comments from PSTs centred around "keeping the students engaged" or "ensuring I involved a lot of group discussion", "giving praise and feedback" and "asking and modelling questions". 


\section{Question 3}

To capture the effectiveness of their micro-teaching lesson, PSTs were asked to rate themselves on presence, effective introduction, sustained communication and conclusions (Figure 5).

\begin{tabular}{|c|c|c|c|c|c|c|c|}
\hline . & $\begin{array}{l}\text { NOT MET } \\
\text { SUITABLE } \\
\text { STANDARD }\end{array}$ & DEVELOPING - & $\begin{array}{l}\text { MET } \\
\text { STANDARD }\end{array}$ & CONSISTENTLY = & $\begin{array}{l}\text { EXCEEDS } \\
\text { SUITABLE } \\
\text { STANDARD }\end{array}$ & TOTAL * & $\begin{array}{l}\text { WEIGHTED } \\
\text { AVERAGE }\end{array}$ \\
\hline - Presence & $\begin{array}{r}1.60 \% \\
6\end{array}$ & $\begin{array}{r}25.94 \% \\
97\end{array}$ & $\begin{array}{r}43.85 \% \\
164\end{array}$ & $\begin{array}{r}25.40 \% \\
95\end{array}$ & $\begin{array}{r}3.21 \% \\
12\end{array}$ & 374 & 3.03 \\
\hline $\begin{array}{l}\text { - Effective introduction of } \\
\text { topic }\end{array}$ & $\begin{array}{r}1.60 \% \\
6\end{array}$ & $\begin{array}{r}28.07 \% \\
105\end{array}$ & $\begin{array}{r}41.98 \% \\
157\end{array}$ & $\begin{array}{r}25.94 \% \\
97\end{array}$ & $\begin{array}{r}2.41 \% \\
9\end{array}$ & 374 & 2.99 \\
\hline $\begin{array}{l}\text { - Sustained } \\
\text { explanation/communication/ }\end{array}$ & $\begin{array}{r}1.33 \% \\
5\end{array}$ & $\begin{array}{r}26.93 \% \\
101\end{array}$ & $\begin{array}{r}36.80 \% \\
138\end{array}$ & $\begin{array}{r}32.00 \% \\
120\end{array}$ & $\begin{array}{r}2.93 \% \\
11\end{array}$ & 375 & 3.08 \\
\hline $\begin{array}{l}\text { Conclusion-Clarification of } \\
\text { student }\end{array}$ & $\begin{array}{r}3.49 \% \\
13\end{array}$ & $\begin{array}{r}33.51 \% \\
125\end{array}$ & $\begin{array}{r}35.66 \% \\
133\end{array}$ & $\begin{array}{r}24.93 \% \\
93\end{array}$ & $\begin{array}{r}2.41 \% \\
9\end{array}$ & 373 & 289 \\
\hline
\end{tabular}

Figure 5. Perceived effectiveness of lesson

In terms of lesson components, PSTs showed more confidence with introductions (70\%) than conclusions (61\%). Much concern related to time management issues with comments such as "I realised I was running out of time so rushed the conclusion", "I felt pressured to finish the lesson in 10 minutes", "I was surprised how fast time passed" and "I let time get the better of me and made a rookie mistake". Other concerns related to nervousness, presence, engagement, unpreparedness and minor hiccups. PSTs reflected on their need to be "more focused, engaging, questioning skills, scaffolding, relevant and concept driven". Over half of the PSTs discussed their "desire to improve, do better, perform in more depth, be more effective, and plenty to reflect upon".

\section{Question 4}

PSTs were asked to reflect on their engagement levels in terms of gaining attention, questioning, appropriate responses and maintaining interest. Of these four, PSTs considered it more difficult to maintain interest (34\% not meeting the standard) and gaining attention (30\% not meeting) rather than respond to students (23\%) and questioning (19\%). PSTs were able to judge if students were engaged or not even if they were confused about how the system worked: "It was difficult to know whether any disengagement was designed to challenge me or if it was an algorithm for when the avatars were not being controlled".

In regards to how to engage avatars (Figure 6), over 30\% of students stated the importance of questioning, $27 \%$ discussed the need for lesson plans, $26 \%$ explained the importance of finding the children's area of interest and $15 \%$ recognised the need to respond appropriately. PSTs commented on specific actions, for example, "noticed, responded, attentive, discussed, challenged, involved, viewed, encouraged, judged and choose." Of the $34 \%$ of PSTs who had difficulty maintaining interest, the majority were able to comment on their impact on avatars:

I found they were not as enthusiastic as I had hoped.

My lesson was foreign to them no wonder they didn't engage.

I managed to link in some interest.

The text was too difficult.

I feel like the Maths was probably a bit boring.

There was little room for them to act up. 


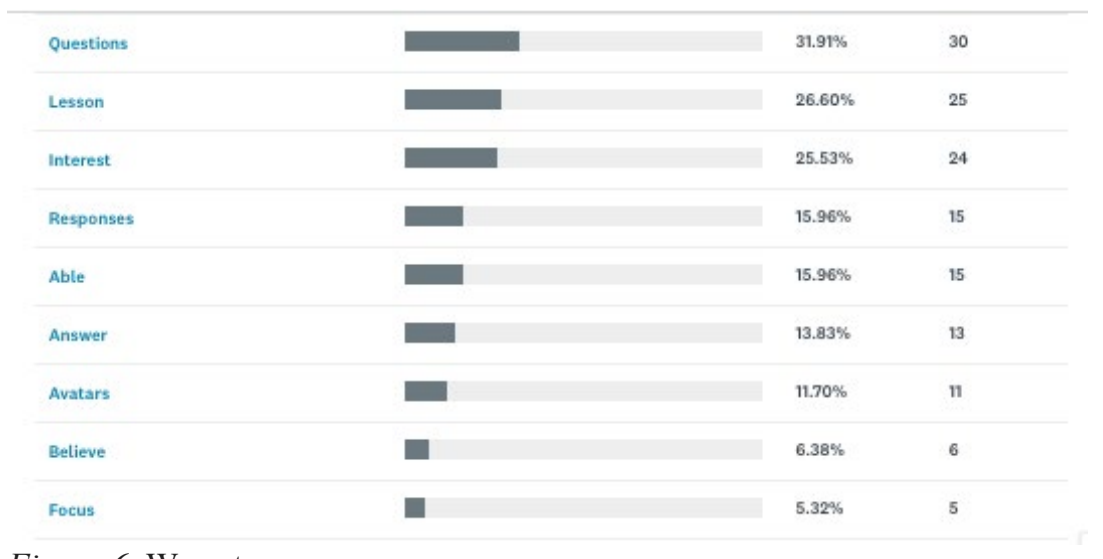

Figure 6. Ways to engage

Question 5

PSTs were asked to reflect on their body language and voice by rating their body language, varied tone and expression, appropriate to situation, clear and audible. Varied tone and expression was the identified area of greatest need, with many PSTs commenting on their need to "improve or alter tone, overcome nervousness, modulate voice, be expressive, slow down, talk clearer, not overuse words like fantastic or guys". Many PSTs commented on their inability to adjust body language when using resources such as the whiteboard or books, expressing concern that "I could focus more on the students rather than turning to use the whiteboard", "I didn't know how to position myself when reading".

PSTs were aware of the impact of body language on their lessons: "This is an area I definitely need to improve on, I felt so overwhelmed and my mind went blank as I entered the lab. I feel my body language and voice would have express how I was feeling". This section provided the most comments related to the viewing of their performance: "Although I thought I was expressive, when I viewed my lesson I sounded really monotonous and monotone", "I didn't think I was nervous but I saw I kept scratching my leg even though it wasn't itchy". Others reflected on their character: "I'm an extrovert so it was easy to be bubbly and energetic", "When I am nervous, I tend to blend my words or use the same phrase, over it's something I have to work on". Some reflected on their growth:

I felt I was quite shielded when I stood in front of the students, looking quite guarded, that slowly improved throughout the lesson. I also turned to look at my lesson plan and remember what questions to ask more than I would have liked.

\section{Question 6}

Feedback involves being able to draw out knowledge, respond to questions, articulate expectations and redirect off-task behaviour (Figure 7). PSTs responded to this question with considerable variance. Many found it difficult to redirect off-task behaviours, with over four times as many PSTs reporting that they do not meet the criteria at all. Most comments related to how PSTs would adjust their actions:

I missed the opportunity to redirect the students through nervousness.

I could have extended their answers and drawn out their responses more.

I feel I need to work on my ability to respond to students in a clarifying way needs developing.

Conversely some blamed other factors:

Due to time constraints it was important to keep lesson flowing and not get too caught up in any disengagement.

I did not want to enter into a power struggle with her about this, as it would have wasted valuable time and further disengaged the other students. 
Some reflections were insightful: "I think I need to work most on my positive reinforcement and redirection of off task students and behaviours. I plan to observe how my mentor teacher deals with these two areas for more ideas".

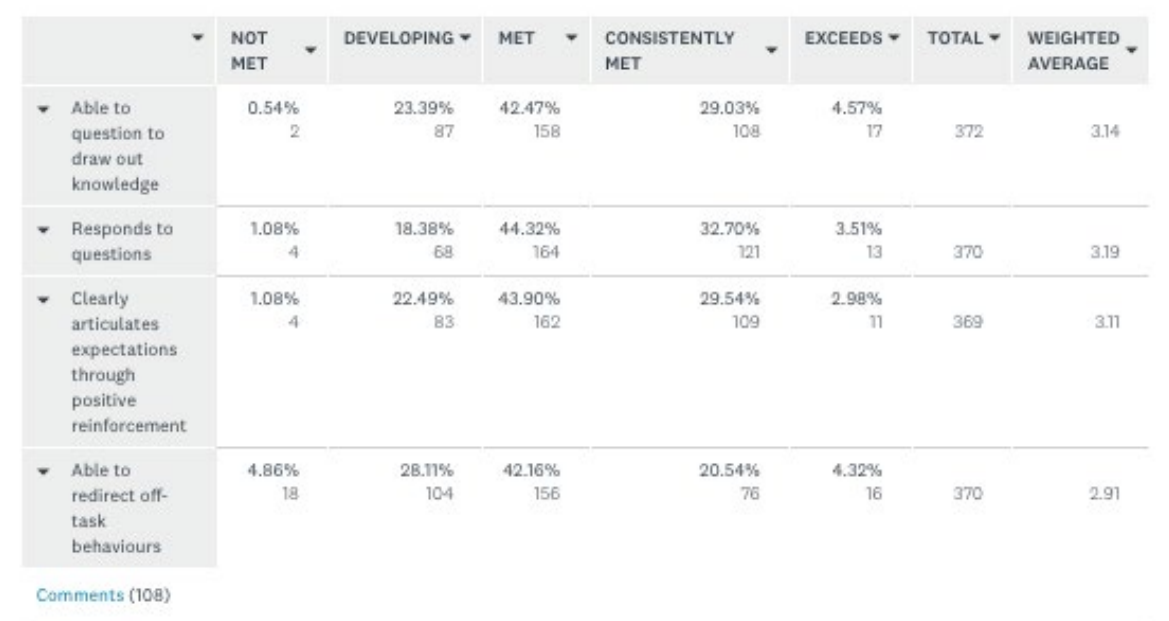

Figure 7. Ability to provide feedback

Question 7

PSTs were asked about their rapport-building ability, in particular eye contact, use of names, interaction, positive/smiles. The word cloud in Figure 8 highlights the collective response.

\section{Discussion $_{\text {Name Tags }} S_{\text {Skype }}$ Nervous $S_{\text {ssion }}$ Continued

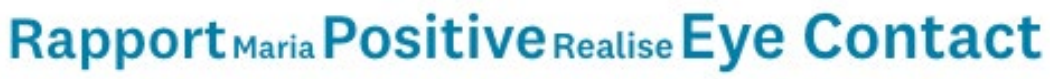 Laughed Interact story Lesson solid Tried Nerves Asked Improved Addressed completed Teachlive Gave Screen}

Figure 8. Response to rapport building

The following comments are indicative of the confidences and perceived ability of PSTs to reflect on their situated practice:

As I was reading I did not really begin to connect to the avatars until we began the questions section of the lesson, and watching it back I saw signs of boredom and fidgeting that I missed during the class. I will need to work on my ability to read and interact/make eye contact simultaneously.

Comments specifically focusing on the technologies included:

Interacting with the TeachLivE interface was rather confusing at first, as it was unfamiliar, once I got comfortable with interacting with the avatars, my rapport building improved.

The fact that the avatars felt like actual students made it easy to build rapport with all of them. Their individual personalities also helped with this.

I did notice that in each attempt I only interacted with 4 out of the five avatars. At the end of both attempts though, I had interacted with each avatar. I need to make sure that in my next attempt I am able to engage all the avatars in one session. 
Question 8

When asked about the benefits or challenges of Micro-teaching 2.0, PSTs' responses were extensive. These reflections have been synthesised and grouped using Van Manen's (1977) three levels of reflection (technical, practical and critical).

\section{Overall benefits}

Technical

Direct feedback, easy to engage, I found the system surprisingly clever, I love the way that the avatars were really responsive and even their little mannerisms and traits were evident, technology connected me from afar, easy to connect, timer in top corner helped schedule, access to video of interaction vital.

\section{Practical}

Improves confidence, great to practice strategies, release nerves before practicum, without stress, low risk, see how lesson flows, great for improving public speaking, good to calm your nerves, gives a rough idea on what you are dealing with, develop language skills, improved organisation skills, developed time management and classroom management, practise in a safe context, it allows you to teach and rehearse, don't need a class of real students as guinea pigs, don't feel the pressure of messing something up, if mistakes are made then it is not detrimental to a child's education, main benefit being able to review the video and reflect on my performance, if anxious puts us out of our comfort zone, it greatly improved my confidence in presenting lesson, it acts as a stepping stone to real life teaching, safe to fail environment, greater insight into real classroom contexts.

\section{Critical}

Highlights your strengths and weaknesses, we learn from doing, reinforced need to deliver clear and purposeful lessons/tasks, reviewing progress over time is going to be helpful, has ability to improve the quality of us as PSTs and ultimately teachers, flexible tool for lots of teaching scenarios, it should be university wide.

\section{Overall challenges}

Technical

Make it less confronting for those overwhelmed by VR technology, I want to use visual reinforcement with pictures and possible power-point presentations with avatars, inbuilt risk of reliance on technology, booking time was a massive confusion and hassle, difficult mastering external connections with juggling phone so next time I will simply use the computer.

\section{Practical}

It doesn't really feel like a lesson it just feels really fake and I feel a little bit silly doing it, limited by 10 minutes, I felt like I was in front of a judging panel, one of the challenges is holding a lesson where students are required to produce work as I am not sure whether the program has those capabilities, better answers for age specific avatars, more off-task behaviours to occur to practice managing classroom.

\section{Critical}

Challenging knowing there is a real person behind the avatars, would be useful if we could access multiple times, nothing beats being in an actual classroom.

The findings confirm the significance of situated learning and reflective practice ideologies within Microteaching 2.0 practices and the impact it has on PSTs' self-efficacy.

\section{Discussion}

The authors have presented Micro-teaching 2.0 as a process for knowledge transfer in ITE. Knowledge of the situational context in addition to practicum is important for developing spontaneous skilful execution (Schön, 1983). Whilst debate exists about the various types of reflective practice and action underpinning spontaneous skilful execution - intuitive, reflective, emotive or developmental (Dewey, 1933; Schön, 1983; Valli, 1997; Van Manen, 1977) - reflection-on-action remains a powerful change agent. It affirms Zeichner's (1994) call for the inclusion of reflective practice strategies in ITE programs. 
The following discussion is framed by the research questions in relation to the findings.

\section{What is Micro-teaching 2.0?}

Micro-teaching 2.0 combines traditional micro-teaching processes originating from Stanford University (Allen \& Eve, 1968) with HITL simulation technologies originating from the University of Central Florida (Dieker, Straub, Hughes, Hynes, \& Hardin, 2014). The addition of a synchronous mixed reality learning environment to the process of micro-teaching offers a safe context to practise the art and science of teaching and enables reflective practice processes to be recorded and reviewed. It overcomes previous microteaching concerns related to peer role plays and asynchronous simulation.

\section{What are the benefits and challenges of Micro-teaching 2.0?}

The findings evidence that Micro-teaching 2.0 benefits far outweigh the challenges. PSTs' reflections were supported by academic observations; they also aligned with the benefits espoused within situated learning and reflective practice ideologies (Lave \& Wagner, 1991). The benefits of Micro-teaching 2.0 impact multiple stakeholders: PSTs' improved self-efficacy, a diagnostic tool for academics and better prepared graduates for the workforce. Interestingly, reflections on benefits related to practical and critical impacts, whilst challenges related more to technical and practical impacts.

\section{What is the impact of Micro-teaching 2.0 on the self-efficacy of PSTs?}

The Micro-teaching 2.0 process reinforces learning through doing and reflective practice (Dewey, 1933: Lave \& Wagner, 1991; Schön, 1983) as part of knowledge transfer (Grossman, 2005). Increased selfefficacy of PSTs was evidenced in Figure 1 and key concepts synthesised below.

PSTs articulated support for Micro-teaching 2.0 and its capacity to improve their confidence and preparedness for real classroom contexts. Some offered examples of its usefulness:

The lesson I planned for Micro-teaching 2.0 was the best lesson I had on placement.

Staying abreast of technological advances that support learning and teaching is essential as a future teacher.

Time to simply talk to a group of children because not all of us have experience with kids.

We talk about Socratic questioning but until you engage with children it doesn't really sink in.

These comments resonate with Peterson's (2014) call for practising, responding and initiating conversations with children as part of ITE programs.

Micro-teaching 2.0 reinforces the importance of reflective practice and situated learning within ITE programs. It offers a unique preparatory tool for PSTs by providing a controlled learning environment that has the capacity to depict a range of authentic contexts and scenarios. It was considered an effective tool for academics to moderate and diagnose the strengths and weaknesses of PSTs without the complexity experienced assessing practicum performance in variable school contexts.

\section{Limitations}

Whilst the authors acknowledge the limitations of self-reporting, such as bias, selective recall, question phrasing and social desirability responses, they have tried to mitigate against these limitations by including observations of simulated experiences by academics and large participant numbers and combining a range of question and response types that were short, simple and with no leading questions. A critical lens was employed to identify the benefits and challenges of Micro-teaching 2.0 in providing a balanced perspective to the discussion. Self-reporting is justified in this study; it is considered an essential methodology to capture the self-efficacy of PSTs and its utility enabled a greater number of participants to be included. 


\section{Conclusion}

Initial teacher educators continue to search for ways to better prepare PSTs for the demands of real classrooms and the ongoing scrutiny of PST quality and preparedness. The principles and practices embedded in Micro-teaching 2.0 offer a practical solution to these concerns. It has the capacity to be a game changer for ITE programs. Its combination of traditional micro- teaching processes with innovative HITL simulated technologies is offered as a virtual learning space for knowledge transfer involving theory, practice and reflection. The controlled learning environment offers a safe place to monitor, practise and master the art of teaching, unlike the variability and complexity of school contexts in which PSTs are currently assessed.

Micro-teaching 2.0 draws from situated learning and reflective practice ideologies to develop PSTs' spontaneous skilful execution of practice (Schön, 1983) and in turn increase the self-efficacy of teaching graduates. It has the capacity to be a diagnostic tool for early identification of the quality and specific needs of PSTs enrolled in ITE programs. The comparability between internal and external students enables easier monitoring of progress and quality.

The authors recommend continued research into the adaptability of Micro-teaching 2.0 and a more systematic approach to the adoption of HITL technologies, rather than what appears to be traditional adhoc, random pockets of technological uptake found across the ITE sector.

\section{References}

Allen, D. W (1980). Micro-teaching a personal review. British Journal of Teacher Education, 6(2), 147151. https://doi.org10.1080/0260747800060206

Allen, D. W., \& Eve, A. W. (1968). Microteaching. Theory into Practice, 7(5), 181-185. https://doi.org/10.1080/004058468095421

Arsal, Z. (2014). Microteaching and pre-service teachers' sense of self-efficacy in teaching. European Journal of Teacher Education, 37(4), 453-464. https://doi.org/10.1080/02619768.2014.912627

Bahr, N., \& Mellor, S. (2016). Building quality in teacher education. Melbourne, Australia: Australian Council for Educational Research. Retrieved from https://research.acer.edu.au/aer/15/

Bandura, A. (1997). Self-efficacy: The exercise of control. New York, NY: W. H. Freeman.

Beauchamp, C. (2006). Understanding reflection in teaching: A framework for analysing the literature (Unpublished doctoral dissertation). McGill University, Montreal, Canada.

Chini, J., Straub, C., \& Thomas, K. (2016). Learning from avatars: Learning assistants practice physics pedagogy in a classroom simulator. Physical Review Physics Education Research, 12(1). https://doi.org/10.1103/PhysRevPhysEducRes.12.010117

Choi, W., Ollivier, D., Chan, T., Schijven, M., Lajoie, S., Mancini, M. E., ... Aggarwal, R. (2017). Engagement and learning in simulation: Recommendations of the Simnovate Engaged Learning Domain Group. BMJ Simulation and Technology Enhanced Learning, 3(1). https://doi.org/10.1136/bmjstel-2016-000177

Christensen, R., Knezek, G., Tyler-Wood, T., \& Gibson, D. (2011). simSchool: An online dynamic simulator for enhancing teacher preparation. International Journal of Learning Technology, 6(2), 201-220. https://doi.org/10.1504/IJLT.2011.042649

Collin, A., Karsenti, R., \& Komis, V. (2013). Reflective practice in initial teacher training: Critiques and perspectives. Multidisciplinary Perspectives, 14(1), 104-117. https://doi.org/10.1080/14623943.2012.732935

Cooper, J., \& Allen, D. (1970). History and present status. Retrieved from ERIC database. (ED036471)

Dalgarno, B., \& Lee, M.J.W. (2010). What are the learning affordances of 3D virtual environments? British Journal of Educational Technology, 40(1), 10-32. https://doi.org/10.1111/j.14678535.2009.01038.x

Darling-Hammond, L. (2016). Research on teaching and teacher education and its influences on policy and practice. Educational Researcher, 45(2), 83-91. https://doi.org/10.3102/0013189X16639597

Department of Education and Training. (2017). Action now: Classroom ready teachers. Canberra, Australia: Author. Retrieved from https://docs.education.gov.au/node/36785/

Dewey, J. (1933). How we think: A restatement of the relation of reflective thinking to the educative process. Boston, MA: DC Heath \& Co. 
Dieker, L. A., Lignugaris-Kraft, B., Hynes, M., \& Hughes, C. E. (2016). Mixed reality environments in teacher education: Development and future applications. In B. Collins \& B. Ludlow (Eds.), Distance education in rural special education (pp. 122-131). Louisville, KY: American Council for Rural Special Educators.

Dieker, L. A., Rodriquez, A., Lignugaris-Kraft, B., Hynes, M., \& Hughes, C. (2014). The potential of simulated environments in teacher education: Current and future possibilities. Teacher Education and Special Education, 37(1), 21-33. https://doi.org/10.1177/0888406413512683

Dieker, L. A., Straub, C., Hughes, C., Hynes, M. C., \& Hardin, S. E. (2014). Learning from virtual students. Educational Leadership, 71(8), 54-58. Retrieved from http://www.ascd.org/publications/educational-leadership/may14/vol71/num08/toc.aspx

Donnelly, R., \& Fitzmaurice, M. (2011). Towards productive reflective practice in microteaching, Innovations in Education and Teaching International, 48(3), 335-346, https://doi.org/10.1080/14703297.2011.593709

Dudley, P, (2011). Lesson Study development in England: From school networks to national policy. International Journal for Lesson and Learning Studies, 1(1), 85-100. https://doi.org/10.1108/20468251211179722

Ell, F., Simpson, A., Mayer, D., McLean Davies, L., Clinton, J., \& Dawson, G. (2019). Conceptualising the impact of initial teacher education. The Australian Educational Researcher, 46, 177-200. https://doi.org/10.1007/s13384-018-0294-7

Ersozlu, Z., Ledger, S., Mayne, F., \& Wildy, H. (2019). Mixed reality learning environments in teacher education: An analysis of TeachLivETM research. Manuscript submitted for publication.

Ferry, B., Kervin, L. K., Cambourne, B., Turbill, J. B., Hedberg, J., \& Jonassen, D. (2005). Incorporating real experience into the development of a classroom-based simulation. Journal of Learning Design, 1(1), 22-32. https://doi.org/10.5204/jld.v1i1.5

Fouts, J.T. (2000). Research on computers and education: Past, present and future (Report). Seattle, WA: Bill and Melinda Gates Foundation. Retrieved from http://portical.org/fouts.pdf

Fox, J., Ahn, S. J. G., Janssen, J. H., Yeykelis, L., Segovia, K. Y., \& Bailenson, J. N. (2015). Avatars versus agents: a meta-analysis quantifying the effect of agency on social influence. Human-Computer Interaction, 30(5), 401-432. https://doi.org/10.1080/07370024.2014.921494

Gibson, J. (1986). The ecological approach to visual perception. Suffolk, UK: Taylor \& Francis.

Gil, M., Pelechano V., Fons J., \& Albert M. (2016). Designing the human in the loop of self-adaptive systems. In C. García, P. Caballero-Gil, M. Burmester, \& A. Quesada-Arencibia (Eds.), Ubiquitous computing and ambient intelligence (vol .10069, pp. 437-449). Zurich, Switzerland: Springer.

Gore, J. (2018, August). Making a difference through Quality Teacher Rounds: Evidence from a sustained program of research. Keynote presentation at the Teaching Practices that make a Difference: Insights from Research Conference, Sydney, Australia.

Gore, J., Griffiths, T., Ladwig, J. (2004). Towards better teaching: Productive pedagogies for teacher education. Teaching and Teacher Education, 20(4), 375-387. https://doi.org/10.1016/j.tate.2004.02.010

Gregory, S., \& Masters, Y. (2012). Real thinking with virtual hats: A role-playing activity for pre-service teachers in Second Life. Australasian Journal of Educational Technology, 28(3), 420-440.

Griffiths, J. (2016). Bridging the school placement gap with peer micro-teaching lesson study. International Journal for Lesson and Learning Studies, 5(3), 227-238. https://doi.org/10.1108/IJLLS11-2015-0035

Grossman, P. (2005). Research on pedagogical approaches in teacher education. In M. Cochran-Smith \& K. Zeichner (Eds.), Review of research in teacher education (pp. 425-476). Washington, DC: American Educational Research Association.

Henderson, M., Huang, H., Grant, S. \& Henderson, L. (2012). The impact of Chinese language lessons in a virtual world on university students' self-efficacy beliefs. Australasian Journal of Educational Technology, 28(3), 400-419. https://doi.org/10.14742/ajet.842

Hixon, E., \& So, H. J. (2009). Technology's role in field experiences for preservice teacher training. Journal of Educational Technology \& Society, 12(4), 294-304. Retrieved from https://www.learntechlib.org/p/74980/

Impedovo, M. A., \& Khatoon Malik, S. (2016). Becoming a reflective in-service teacher: Role of research attitude. Australian Journal of Teacher Education, 41(1). https://doi.org/10.14221/ajte.2016v41n1.6

Kemmis, S., Wilkinson, J., Edwards-Groves, C., Hardy, I., Grootenboer, P., \& Bristol, L. (2014). Changing practices, changing education. Singapore: Springer. https://doi/10.1007/978-981-4560-47-4 
Kraft, M., Marinell, W., \& Yee, D. (2016). School organizational contexts, teacher turnover, and student achievement. American Educational Research Journal, 5(5), 1411-1449. https://doi.org/10.3102/0002831216667478

Lave, J., \& Wenger, E. (1991). Situated learning: Legitimate peripheral participation. Cambridge, England: Cambridge University Press. https://doi.org/10.1017/CBO9780511815355

Le Cornu, R. (2016). Professional experience: Learning from the past to build the future. Asia-Pacific Journal of Teacher Education, 44(1), 80-101. https://doi.org/10.1080/1359866X.2015.1102200

Ledger, S. (2016). TeachLive at Murdoch University [Television news article]. Retrieved from https://vimeo.com/212524840

Ledger, S. (2017). Learning to teach with avatars (Innovative case study). Perth, Australia: Murdoch University. Retrieved from http://app.iru.edu.au/national-innovation-case-study-collection\#browseby-theme/theme-details/58e5e58693455a4910526992/?view 125 page $=2$

Ledger, S., Ersozlu, Z., \& Fischetti, J. (2019). Preservice teachers' confidence and preferred teaching strategies using TeachLivE ${ }^{\mathrm{TM}}$ virtual learning environment: A two-step cluster analysis. Eurasia Journal of Mathematics, Science and Technology, 15(3) em1674. https://doi.org/10.29333/ejmste/102621

Lewis, C. (2002). Does Lesson Study have a future in the United States? Nagoya Journal of Education and Human Development, 1(1), 1-23. Retrieved from ERIC database. (ED472163)

Lichtman, M. (2006). Qualitative research in education: A user's guide. London, CA: Sage.

Louden, W. (2008). 101 damnations: The persistence of criticism and the absence of evidence about teacher education in Australia. Teachers and Teaching, 14(4), 357-368. https://doi.org/10.1080/13540600802037777

Lui, D., Dede, C., Jacobson, J., \& Richards, J. (2017). Virtual, augmented, and mixed realities in education. Smart Computing and Intelligence Series. Singapore: Springer. https://doi.org/10.1007/978-981-10-5490-7

Mayer, D., Allard, A., Bates, R., Dixon, M., Doecke, B., Kline, J., ... Hodder, P. (2015). Studying the effectiveness of teacher education: Final report. Geelong, Australia: Deakin University. Retrieved from http://www.setearc.com.au/wp-content/uploads/2013/08/SETE_report_FINAL 30.11.152.pdf

Mergler, A., \& Tangen, D. (2010). Using microteaching to enhance teacher efficacy in pre-service teachers. Teaching Education, 21(2), 199-210. https://doi.org/10.1080/10476210902998466

Murdoch University. (n.d.). SimLab: A mixed reality learning environment for teaching preparation and professional learning. Retrieved from https://www.murdoch.edu.au/pages/simlab

Mursion. (2017). Scheduling manual for Mursion. Retrieved from https://scheduling.mursion.com/resources/download/Mursion_SimLab_EquipmentList.pdf

Nagendran, A., Pillat, R., Kavanaugh, A., Welch, G., \& Hughes, C. (2014). A unified framework for individualized avatar-based interactions. Presence, 23(7), 109-132. https://doi.org/10.1162PRES a 000177

Newton, D. P. (1983). Computer simulation in teacher training. Journal of Further and Higher Education, 7(3), 47-54. https://doi.org/10.1080/0309877830070306

Peterson, M. B. (2014). Pre-service special education teachers' frequency of opportunities to respond in the TeachLivE ${ }^{\mathrm{TM}}$ virtual classroom (Doctoral dissertation). Retrieved from ProQuest database. (3623983)

Remesh, A. (2013). Microteaching: An efficient technique for learning effective teaching. Journal of Research in Medical Sciences, 18(2), 158-163. Retrieved from https://www.ncbi.nlm.nih.gov/pubmed/23914219

Schleicher, A. (2011, March). Building a high-quality teaching profession: Lessons from around the world. Presentation at the Organisation for Economic Co-operation and Development International Summit on the Teaching Profession, New York. Retrieved from http://www.oecd.org/education/school/programmeforinternationalstudentassessmentpisa/4750617

Schön, D. (1983). The reflective practitioner: How professionals think in action. New York, NY: Basic Books.

Schwabb, K. (2017). Fourth Industrial Revolution. New York, NY: Penguin. Retrieved from https://www.weforum.org/about/the-fourth-industrial-revolution-by-klaus-schwab

Straub, C., Dieker, L., Hynes, M., \& Hughes, C. (2015). Using virtual rehearsal in TLE TeachLivE ${ }^{\mathrm{TM}}$ mixed reality classroom simulator to determine the effects on the performance of mathematics teachers (Report). Retrieved from http://teachlive.org/wpcontent/uploads/2014/10/2014_GR_Technical_Report_10_20_FINAL.pdf 
Tripp, D. (2005). Action research: A methodological introduction. Educacao e pesquisa, 31(3) 443-466. https://doi.org/10.1590/S1517-97022005000300009

Tyler-Wood, T., Estes, M, Christensen, R., Knezek, G. \& Gibson, D. (2017). SimSchool: An opportunity for using serious gaming for training teachers in rural areas. Rural Special Education Quarterly, 34(3), 17-20. https://doi.org/10.1177/875687051503400304

Ure, C., Hay, I., Ledger, S., Morrison, C., Sweeny, T., \& Szadura, A. (2018). Professional experience in initial teacher education: A review of current practices in Australian ITE. Canberra, Australia: Australian Council Deans of Education. Retrieved from https://www.acde.edu.au/wpcontent/uploads/2018/06/Final-Report-NADPE-Project-Revised-March-2018.pdf

Valli, L. (1997). Listening to other voices: A description of teacher reflection in the United States. Peabody Journal of Education, 72(1), 67-88. https://doi.org/0.1207/s15327930pje7201 4

Van Manen, M. (1977). Linking ways of knowing with ways of being practical. Curriculum Inquiry, 6(3), 205-228. https://doi.org/10.1080/03626784.1977.11075533

Vare, J. W. (1993). Co-constructing the zone: A neo-Vygotskian view of microteaching. Retrieved from ERIC database. (ED360285)

Vygotsky, L. (1980). Mind in society: The development of higher psychological processes. Cambridge, MA: Harvard University Press.

Zeichner, K. (1987). Preparing reflective teachers: An overview of instructional strategies which have been employed in preservice teacher education. International Journal of Education Research, 11(5), 565-576. https://doi.org/10.1016/0883-0355(87)90016-4

Zeichner, K. (1994). Research on teacher thinking and different views of reflective practice in teaching and teacher education. In I. Carlgren, G. Handal, \& S. Vaage (Eds.), Teachers' minds and actions: Research on teachers' thinking and practice (pp. 9-24). London, UK: The Falmer Press.

Corresponding author: Susan Ledger, s.ledger@murdoch.edu.au

Copyright: Articles published in the Australasian Journal of Educational Technology (AJET) are available under Creative Commons Attribution Non-Commercial No Derivatives Licence (CC BY-NC-ND 4.0). Authors retain copyright in their work and grant AJET right of first publication under CC BY-NC-ND 4.0.

Please cite as: Ledger, S., \& Fischetti, J. (2020). Micro-teaching 2.0: Technology as the classroom. Australasian Journal of Educational Technology, 36(1), 37-54. https://doi.org/10.14742/ajet.4561 